\title{
Treatment Evaluation of Melasma Patients in Dr. Hasan Sadikin General Hospital Bandung in period of 2013-2014
}

\author{
Ayu Adzani Sabila, ${ }^{1}$ Reti Hindritiani, ${ }^{2}$ Dimas Erlangga Luftimas ${ }^{3}$ \\ ${ }^{1}$ Faculty of Medicine Universitas Padjadjaran, ${ }^{2}$ Department of Dermatology and Venereology \\ Faculty of Medicine Universitas Padjadjaran/Dr. Hasan Sadikin General Hospital Bandung, \\ ${ }^{3}$ Department of Medical Nutrition Faculty of Medicine Universitas Padjadjaran
}

\begin{abstract}
Background: Melasma is hyperpigmentation of the skin especially located on face exposed to the sunlight. This condition was characterized by brown to gray-brown macula with irregular border. Difficulties in treatment of melasma arise from high tendency for relapse, expensive cost, and high risk of side effects such as erythema, sores, scales, and acne eruption. Study about evaluation of melasma therapy in Dr. Hasan Sadikin General Hospital Bandung have not ever been done before. Therefore, this study was conducted to evaluate therapy of melasma in the Policlinic of Dermatology and Venereology, Dr. Hasan Sadikin General Hospital Bandung.

Methods: This study was retrospectively descriptive. Data were obtained from the new melasma patient medical records of Policlinic of Dermatology and Venereology of Dr. Hasan Sadikin General Hospital Bandung in period of January 2013-2014. Sampling method used in this study was total sampling. Treatments of melasma were evaluated by using Melasma Area Severity Index (MASI) score. Collected data were processed and presented in frequency distribution and percentage.

Results: The most used topical drugs were combination of hydroquinone and tretinoin, and all of patients received sunblock. Most frequent time interval was two weeks (30.8\%). The most common side effect was erythema (10 out of 22). Decreased MASI score was discovered in $48.1 \%$ and the most decreased category was mild (14 out of 25$)$.

Conclusions: The very common topical drugs used are hydroquinone and tretinoin. The side effect of the treatment is Erythema. The decreased MASI score is mild. [AMJ.2016;3(4):610-5]
\end{abstract}

Keywords: Evaluation, melasma, treatment

\section{Introduction}

Melasma is skin hyperpigmentation especially located on face exposed to sunlight. ${ }^{1,2}$ This condition was characterized by brown to gray-brown macula with irregular border. ${ }^{1,3}$ Melasma more frequently occurs in women compared to men and in the dark-skinned people. ${ }^{1,3}$ This disease can be found in the average age of $27.5 \pm 7.8$ years old and rarely found in puberty. ${ }^{4}$ This condition affects more than five million people in America and 7760 patients have been found in Ethiopia. ${ }^{4}$ Another studies from Peru and Lebanon discovered $10.11 \%$ and $3.4 \%$ patients with melasma, respectively. ${ }^{4}$ In Southeast Asian, melasma was complained by $0.25-4 \%$ patients. ${ }^{5,6} \mathrm{~A}$ study in Brazil using Melasma Quality of Life Scale showed that $65 \%$ of patients felt uncomfortable, 55\% felt frustrated and 57\% felt embarrassed experiencing melasma. ${ }^{5}$

The treatment of melasma in each person is different and needs long term treatment.,8 Difficulties in treatment of melasma arise from high tendency for relapse, expensive cost and high risk of side effects such as erythema, sores, scales and acne eruption. ${ }^{3,8}$ Standard therapy of melasma in Department of Dermatology and Venereology of Dr. Hasan Sadikin General Hospital Bandung according to guideline melisma is divided into two parts; i.e general and specific. General part consists of the use of sunblock, photoprotection and avoidance of precipitating factors. Specific part consists of depigmentation substances

Correspondence: Ayu Adzani Sabila, Faculty of Medicine, Universitas Padjadjaran, Jalan Raya Bandung-Sumedang Km.21, Jatinangor, Sumedang, Indonesia, Phone: +6282118094129 Email: ayuadzani@gmail.com 
such as hydroquinone, kojic acid, and arbutine. Procedure such as chemical peeling and laser procedure are part of specific therapy.

Treatment evaluation can be assessed by Melasma Area Severity Index (MASI).,3 This scoring is calculated by assessing three indicators, i.e area of involvement, darkness and hyperpigmentation homogeneity. ${ }^{2}$ To calculate MASI score, the sum of severity grade for darkness and homogeneity is multiplied by numerical value areas (forehead, right malar, left malar, chin). ${ }^{9,10}$ This scoring ranges from $0-48{ }^{2}$ Melasma is the second most frequent disease after acne vulgaris in the Division of Cosmetic Dermatology of Department of Dermatology and Venereology of Dr. Hasan Sadikin General Hospital Bandung in the period of January 1st ,2011 to December 31st, 2014. Study about evaluation of melasma therapy in Dr. Hasan Sadikin General Hospital Bandung has not ever been done before. Therefore, this study was conducted to evaluate therapy of melasma in the Policlinic of Dermatology and Venereology Dr. Hasan Sadikin General Hospital Bandung.

\section{Methods}

This was a retrospectively descriptive study. Data were obtained from medical records of the new melasma patients in Policlinic of Dermatology and Venereology Dr. Hasan Sadikin General Hospital Bandung for two years from January 2013 to December 2014. This study had been approved by the Ethical Committee of Health Study Dr. Hasan Sadikin General Hospital Bandung through ethical clearance number: LB.04.01/AOS/EC/258/ $\mathrm{VII} / 2015$ and had been given permission by Dr. Hasan Sadikin General Hospital Bandung. Variables in this study were medication, side effects, time interval, and MASI score. Medications of melasma patients were divided into some parts, i.e; applying single or combined depigmentation substance(s),

\section{Score in 2nd visit- score in 1st visit} score in 1st visit

$\begin{array}{ll}\geq 0-25 \% & : \text { mild } \\ >25-50 \% & : \text { moderate } \\ >50 \% & : \text { remarkable reduction }\end{array}$

Figure 1 Formula Used to Calculate The Decrease of the score application of sunblock, systemic medication and laser procedure or chemical peeling. Time interval was several weeks between first and second visit. Side effects were assessed during treatment. Assessment of MASI score was according to the score in the first visit (pre treatment) and the second visit (post treatment).

The criteria of inclusion in this study were all of medical records with melasma along with the MASI scoring in the period of January 2013 to December 2014. The criteria of exclusion in this study were medical records with only one visit.

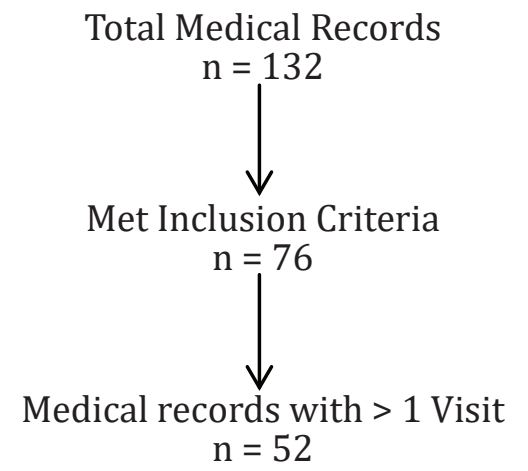

Sampling method used in this study was total sampling. The medical records which met the inclusion and exclusion criteria were then processed and grouped using statistic software. The results of this study were presented in frequency distribution and percentage.

\section{Results}

One of the difficulties encountered in this study was the time interval between the first and the second visit which may affect outcome of the therapy and MASI score. Table 1 showed the medication type of melasma. During two visits, the most administered depigmentation substance was combination of hydroquinone and tretinoin. Beside depigmentation substance, all the melasma patients were given sunblock. Procedure was started in the second visit, and chemical peeling was done.

Distribution of time interval was showed in table 2. Interval between the first and the second visit were two weeks, three weeks, and four weeks respectively.

The side effects were presented in table 3. Side effects was complained by 22 out of 52 patients. Erythema was one of side effects frequently complained.

The changes of MASI score were calculated by subtracting the second visit'ss score from 
Table 1 Distribution of Treatment Variation of Melasma

\begin{tabular}{|c|c|c|c|c|}
\hline \multirow{3}{*}{ Type of Treatment } & \multicolumn{4}{|c|}{ Visits } \\
\hline & \multicolumn{2}{|c|}{ I } & \multicolumn{2}{|c|}{ II } \\
\hline & n & $\%$ & $\mathbf{n}$ & $\%$ \\
\hline \multicolumn{5}{|l|}{ A.Topical Drugs } \\
\hline \multicolumn{5}{|l|}{ 1.Depigmentation Substance } \\
\hline \multicolumn{5}{|l|}{ a. Single } \\
\hline KA & 1 & 1.9 & 2 & 3.8 \\
\hline Tret & 4 & 7.7 & 0 & 0.0 \\
\hline AHA & 0 & 0.0 & 0 & 0.0 \\
\hline \multicolumn{5}{|l|}{ b.Combination } \\
\hline $\mathrm{HQ}+\mathrm{AA}$ & 1 & 1.9 & 1 & 1.9 \\
\hline $\mathrm{HQ}+\mathrm{KA}$ & 0 & 0.0 & 1 & 1.9 \\
\hline $\mathrm{HQ}+$ tret & 30 & 57.8 & 28 & 53.9 \\
\hline $\mathrm{KA}+\mathrm{LA}$ & 1 & 1.9 & 0 & 0.0 \\
\hline $\mathrm{KA}+$ tret & 5 & 9.6 & 6 & 11.9 \\
\hline VitC+tret & 1 & 1.9 & 1 & 1.9 \\
\hline AHA+tret & 0 & 0.0 & 3 & 5.8 \\
\hline $\mathrm{HQ}+$ tret+AHA & 3 & 5.8 & 3 & 5.8 \\
\hline $\mathrm{HQ}+$ tret+cor & 2 & 3.8 & 2 & 3.8 \\
\hline $\mathrm{HQ}+$ tret+Vit C & 3 & 5.8 & 3 & 5.8 \\
\hline $\mathrm{KA}+\mathrm{LA}+\mathrm{AHA}$ & 1 & 1.9 & 1 & 1.9 \\
\hline $\mathrm{KA}+$ tret+AHA & 0 & 0.0 & 1 & 1.9 \\
\hline $\mathrm{KA}+$ tret+VitC & 0 & 0.0 & 0 & 0.0 \\
\hline \multicolumn{5}{|l|}{ 2.Sunblock } \\
\hline Yes & 52 & 100.0 & 52 & 100.0 \\
\hline \multicolumn{5}{|l|}{ B.Procedure } \\
\hline Without Procedure & 52 & 100.0 & 43 & 82.7 \\
\hline Chemical Peeling & 0 & 0.0 & 9 & 17.3 \\
\hline Laser & 0 & 0.0 & 0 & 0.0 \\
\hline Total & 52 & 100.0 & 52 & 100.0 \\
\hline
\end{tabular}

Note: *AA :azelaic acid, AHA :alpha hydroxyl acid, Cor : corticosteroid, HQ :hydroquinone, KA :kojic acid, LA :lactic acid,tret: tretinoin

the first visit's score. The category of MASI score changes were constant, decrease, and increase. MASI score's changes was often decreased. Twenty five decreased of MASI score was grouped into mild, moderate, and remarkable reduction. In the second visit, the mostly decreasing category was mild.

\section{Discussion}

Three main factors that influence the pathogenesis of melasma are genetic, hormonal, and ultraviolet exposure. ${ }^{1,4}$ Ultraviolet exposure is a precipitating factor and it aggravates melasma due to its stimulation to melanocyte. ${ }^{8,11}$ Therefore, photo 
Table 2 Distribution of Time Interval among Visits of Melasma Patients

\begin{tabular}{|c|c|c|}
\hline Time Interval & $\mathbf{n}$ & $\%$ \\
\hline 1 week & 2 & 3.8 \\
\hline 2 weeks & 16 & 30.8 \\
\hline 3 weeks & 12 & 23.1 \\
\hline 4 weeks & 9 & 17.3 \\
\hline 5 weeks & 2 & 3.8 \\
\hline 6 weeks & 1 & 1.9 \\
\hline 7 weeks & 1 & 1.9 \\
\hline 8 weeks & 3 & 5.8 \\
\hline$>8$ weeks & 6 & 11.6 \\
\hline Total & 52 & 100.0 \\
\hline
\end{tabular}

Table 3 Distribution of Side Effects of Melasma Patients

\begin{tabular}{lcc}
\hline & Side Effects & N \\
\hline Erythema & 10 \\
Sore & 5 \\
Scale & 3 \\
Itchiness & 2 \\
Burns & 1 \\
Acne & 1 \\
Total & 22 \\
\hline
\end{tabular}

protection is a part of melasma therapy.,12 In this study, all patients received sunblock in every visit.

The goal of melasma treatment is to inhibit the pigmentation process and remove or destruct the formed melanin. ${ }^{3,7}$ The usage of topical drugs is to inhibit the enzymatic process in pigment production. ${ }^{12}$ The combination of hydroquinone and tretinoin was often used in this treatment. Hydroquinone plays role as the depigmentation agent by inhibiting tyrosinase enzyme, an enzyme used in pigmentation process, ${ }^{12,13}$ while tretinoin plays role in stimulating keratinocyte turnover, destroying formed melanin, and helping hydroquinone penetration to epidermal layer. ${ }^{3,12}$

Table 4 Distribution of Changes and Decreasing MASI Score of Melasma Patients

\begin{tabular}{lcc}
\hline \multicolumn{1}{c}{ Category of MASI Score } & N & \% \\
\hline Changes of MASI Score & & \\
Constant & 21 & 40.4 \\
Decrease & 25 & 48.1 \\
Mild & 14 & - \\
Moderate & 6 & - \\
Remarkable Reduction & 5 & - \\
Increase & 6 & 11.5 \\
Total & 52 & 100.0 \\
\hline
\end{tabular}


In several studies, this use of combination showed better improvement than single therapy. ${ }^{8,12,13}$ Combined therapy can provide more optimal effect.,4,12 Other choices are the combination of hydroquinone, tretinoin and corticosteroid, also known as Kligman Formula. ${ }^{12,13}$ Kligman Formula is the most potent and frequent used by clinicians for melasma therapy. ${ }^{3,12}$ In the study of Azzam et al. ${ }^{14}$ there was a significant decrease in MASI score of patient group. However, the use of this formula is limited to 4 to 8 weeks because of the steroid side effects which can cause skin atrophy, telangiectasis and acneiform eruption. ${ }^{3,7}$

Chemical peeling agents are beneficial in the treatment of melasma and may be used in combination with other forms of melasma treatment. ${ }^{3,6,7}$ The peel solution is selected according to patient's needs, skin type, and sensitivities. ${ }^{3,6,7}$ Many types of chemical peels solutions can be used.,13 Glycolic Acids and Salicylic Acids have been used for many years in the treatment of melasma. ${ }^{13}$ In this study, chemical peeling is the most common procedure. Laser and light therapies for the treatment of melasma have become increasingly popular. ${ }^{12,13}$ The function of laser treatment is to destroy melanin formed. Laser treatment creates an increased risk of adverse effects via direct damage to the skin, so it can cause a paradoxical increase in pigmentation following treatment. ${ }^{12,13}$

The interval between the first and second visit is two weeks. Certain rule about frequency and interval of melasma medication was not found in this study. To assess the evaluation of melasma therapy, Kroon et al. ${ }^{15}$ conducted an observation in the third week, twelfth week and twenty fourth week. ${ }^{15}$ Meanwhile, Farshi ${ }^{16}$ conducted an observation of therapy result in the fourth and eighth week. The possible side effects after medication were erythema, burn, scale, itchiness, sore or even acne eruption. ${ }^{3,14}$ A study of Farshi ${ }^{16}$ showed that as many as $46.6 \%$ patients complained about erythema after one month applying hydroquinone. ${ }^{16}$ A study of Chowdury et al. ${ }^{9}$ showed that as many as $20 \%$ patients complained about erythema, 7\% complained about itchiness, 7\% complained about burn and 3\% complained about scale.

The MASI scoring assesses three factors; area (A), darkness (D) and homogeniety of pigmentation $(\mathrm{H})^{2,9,10}$ To calculate the MASI scoring, face needs to be divided into four area; forehead, right malar, left malar and chin with their percentage of area $(30 \%, 30 \%$,
$30 \%$ and $10 \%$, respectively). The final score of MASI is the addition of hyperpigmentation and homogenicity then multiplied by the melasma area. ${ }^{2,9,10}$ The average of MASI score cannot be included due to the non-normal distribution. The average MASI score in Kroon et al. ${ }^{15}$ study was $8.5 \pm 3.6$ while in Ejaz et al. ${ }^{17}$ study was $6.5 \pm 3.84$

Decreased MASI score means that the patients have improvement in their melasma. ${ }^{2,20}$ Most patients in this study have decreased MASI score in the second visit. In the study of Kroon et al. ${ }^{15}$ there were 8 out of 10 patients experienced the improvement at the second visit after applying Kligman Formula. In this study, some patients had increase MASI score. That condition may be caused by low compliance of using sunblock and other medication usages or by increased exposure to precipitating factors. ${ }^{11,12,14} \mathrm{~A}$ study in Bangladesh ${ }^{9}$ showed that the average decrease of MASI score in the twelfth week of therapy was as many as $24.20 \%$ or mild. Based on category of decreasing MASI, most patients in this study belong to the mild group at the second visit.

Data obtained in this study were based on medical record. Limitation in this study is medical record fulfillment in every patient's visit conducted by different resident doctors. Therefore, different MASI score assessment in every visit leads to the subjectivity of therapy evaluation. ${ }^{2,3}$ Specific choice of treatment and time interval standard is needed for melasma treatment in every visit, therefore it will help in evaluating therapy. Hopefully, data obtained from this study can be used as a consideration in arranging guidelines of melasma more specifically in the Department of Dermatology and Venereology Dr. Hasan Sadikin General Hospital Bandung.

It can be concluded that the most frequent interval between the first and second visit on the melasma patients is two weeks. The combination of hydroquinone and tretinoin is the topical drugs often used for melasma patients. The patients got sunblock and chemical peeling treatment. The side effect often experienced by the patients is erythema. MASI score was frequently decreased which is classified as mild at the second visit.

\section{References}

1. Lapeere H, Boone B, Schepper SD, Verhaeghe E, Gele MV, Ongenae K, et al. Hypomelanoses and hypermelanoses. In: Goldsmith LA, Katz SI, Gilchrest BA, Paller 
AS, Leffell DJ, Wolff K, editors. Fitzpatrick's dermatology in general medicine. $8^{\text {th }}$ ed. New York: Mcgraw-Hill; 2012. p. 804-26.

2. Pandya AG, Hynan LS, Bhore R, Riley FC, Guevara IL, Grimes P, et al. Reliability assessment and validation of the Melasma Area and Severity Index (MASI) and a new modified MASI scoring method. J Am Acad Dermatol. 2011;64(1):78-83.

3. Damevska K. New Aspects of Melasma/ Novi aspekti melazme. Serbian Journal of Dermatology and Venereology. 2014;6(1):5-18.

4. Sheth VM, Pandya AG. Melasma: a comprehensive update: part I. J Am Acad Dermatol. 2011;65(4):689-97.

5. Handel AC, Miot LDB, Miot HA. Melasma: a clinical and epidemiological review. Anais Brasileiros de Dermatologia. 2014;89(5):771-82.

6. Sarkar R, Arora P, Garg VK, Sonthalia $\mathrm{S}$, Gokhale N. Melasma update. Indian Dermatol Online J. 2014;5(4):426-35.

7. Shankar K, Godse K, Aurangabadkar S, Lahiri K, Mysore V, Ganjoo A, et al. Evidence-Based treatment for Melasma: expert opinion and a Review. Dermatology and Therapy. 2014;4(2):165-86.

8. Kang HY, Ortonne J-P. What should be considered in treatment of melasma. Annals of Dermatology. 2010;22(4):373-8.

9. Chowdhury W, Wahab M, Khondker L, Khan M, Shirajul I. Efficacy and Safety of Hydroquinone, Kojic Acid and Glycolic Acid combination in the treatment of Melasma. Banglajol. 2012;11(3):191-6
10. Ghersetich I, Troiano M, Brazzini B, Arunachalam M, Lotti T. Melasma: treatment with $10 \%$ tretinoin peeling mask. J Cosmet Dermatol. 2010;9(2):11721.

11. Rigopoulos D, Gregoriou S, Katsambas A. Hyperpigmentation and Melasma. J Cosmet Dermatol. 2007;6(3):195-202.

12. Sheth VM, Pandya AG. Melasma: a comprehensive update: part II. J Am Acad Dermatol. 2011;65(4):699-714.

13. Rivas S, Pandya AG. Treatment of melasma with topical agents, peels and lasers: an evidence-based review. Am J Clin Dermatol. 2013;14(5):359-76.

14. Azzam OA, Leheta TM, Nagui NA, Shaarawy E, Hay RMA, Hilal RF. Different therapeutic modalities for treatment of melasma. J Cosmet Dermatol. 2009;8(4):275-81.

15. Kroon MW, Wind BS, Beek JF, van der Veen JW, Nieuweboer-Krobotová L, Bos JD, et al. Nonablative 1550-nm fractional laser therapy versus triple topical therapy for the treatment of melasma: a randomized controlled pilot study. J Am Acad Dermatol. 2011;64(3):516-23

16. Farshi S. Comparative study of therapeutic effects of $20 \%$ azelaic acid and hydroquinone $4 \%$ cream in the treatment of melasma. J Cosmet Dermatol. 2011;10(4):282-7.

17. Ejaz A, Raza N, Iftikhar N, Muzzafar $\mathrm{F}$. Comparison of $30 \%$ salicylic acid with Jessner's solution for superficial chemical peeling in epidermal melasma. J Coll Physicians Surg Pak. 2008;18(4):205-8. 